\title{
A PARTICIPAÇÃO ENQUANTO TALISMÃ: UMA REFLEXÃO METAFÓRICA E TEÓRICA SOBRE A CONCEPTUALIZAÇÃo DA PARTICIPAÇÃo
}

\author{
Ignacio Bergillos \\ Departamento de Ciências da Comunicação, Centro de Ensino Superior Al- \\ berta Giménez, Universidade Pontifícia Comillas, Espanha
}

\begin{abstract}
RESUMO
Ainda que a participação tenha sido uma palavra chave para muitas áreas de investigação no âmbito da investigação no âmbito da Comunicação e dos Média, não existe ainda um consenso sobre a sua definição. A coexistência inevitável entre diferentes abordagens ao conceito tem travado o desenvolvimento de uma estrutura teórica única. No entanto, os esforços para conceptualizar a participação e para compreender as crescentes práticas participativas nos/através dos média, nos últimos anos, têm alimentado a área da comunicação e cultura participativas com ideias elucidativas que servem de denominadores comuns para investigações futuras. A maior parte dessas ideias, embora aparentemente contraditórias, seguem padrões e interesses semelhantes que poderiam conduzir a um entendimento partilhado acerca do que é ou deveria ser a participação. Este artigo tenta contribuir para o resgate da participação, ao rever, do ponto de vista teórico, o seu aparato conceptual no campo da investigação em Comunicação e Média, e ao introduzir a ideia de que a participação pode ser conceptualizada através da metáfora do talismã. À semelhança de Lakoff e Johnson (1980), este artigo defende que o modo como conceptualizamos os fenómenos influencia a forma como percebemos as nossas práticas. Se assumirmos que resgatar significa salvar de um perigo ou mal, deveríamos reclamar um entendimento da participação como um poderoso amuleto. Nesse sentido, a revisão teórica das conceptualizações da participação no campo da investigação em Comunicação e Média que este artigo oferece irá defender que a participação poderá, pelo menos parcialmente, ser estruturada, percebida, definida e usada como um talismã. Mais especificamente, o texto irá discutir quatro aspetos que estruturam este conceito metafórico: a participação como uma fantasia, a autenticidade da participação, o ritual da participação e o seu valor (estético).
\end{abstract}

\section{PARTiCipation AS A TAlisman: A MeTAPHORICAL- THEORETICAL REFLECTION ABOUT THE CONCEPTUALIZATION OF PARTICIPATION}

\begin{abstract}
Even if participation has been a key word in many research areas within Communication and Media Studies, there are still theoretical disagreements about its definition. The inevitable coexistence of different approaches to the concept has hindered the development of a unique theoretical framework. However, the efforts to conceptualise participation and to understand the increasing participatory practices in/through media in the last years has nourished the field of
\end{abstract}


participatory communication and participatory culture with insightful ideas that serve as common ground for future research. Most of these ideas, while apparently contradictory, follow similar patterns and interests that could potentially lead to a shared understanding of what participation is or should be. This article tries to contribute to the objective of rescuing participation by theoretically reviewing the conceptual apparatus of participation in Communication and Media Studies and introducing the idea that participation can be conceptualized through the metaphor of the talisman. Following Lakoff and Johnson (1980), this article argues that the way we conceptualize phenomena has an influence on how we perceive our practices. If we assume to rescue as an act to save from danger or evil, we should reclaim an understanding of participation as a powerful amulet. In that sense, the theoretical review of the conceptualizations of participation in the field of Media and Communication Studies that this article offers, will argue that participation can, at least partially, be structured, understood, defined and used in terms of a talisman. Specifically, the text will discuss four aspects that structure this metaphorical concept: participation as a fantasy, the authenticity of participation, the ritual of participation, and its (aesthetic) value.

KEYWORDS

fantasy; media studies; metaphorical concept; participation; power

\section{INTRODUÇÃO}

Se existe a necessidade de resgatar a participação é porque, muitas vezes, no âmbito dos Estudos em Comunicação e Média, este tem sido um conceito pouco debatido. Apesar do caráter central da participação em muitos dos discursos, abordagens e análises, o seu uso em diversos contextos acabou por se tornar num termo vasto e indefinido. Segundo Carpentier (2011a, pp. 353-354), "num determinado momento a participação deixa simplesmente de ser participação. A participação é um significante que pode assumir significados diferentes muitos significados diferentes. Potencial e teoricamente pode mudar para qualquer outra direção". De um modo semelhante, Jenkins, Ito \& boyd $(2016$, p. 181) realçam o facto de

precisarmos de um vocabulário mais refinado para distinguir modelos concorrentes/opostos de participação, especialmente numa altura em que a sua retórica é utilizada por instituições que pouco ou nada fizeram para permitir que o maior número possível de pessoas diferentes possa participar.

A conceptualização da participação é uma tarefa complexa: mesmo que consideremos as múltiplas abordagens acerca de como defini-la do ponto de vista teórico, poderemos ser acusados de imprecisão, tendo em conta a abrangência do termo. Contudo, é importante defender, como Reifová e Svelch (2013 p. 264), que "em vez de descartarmos o conceito de participação, deveríamos atribuir-lhe significado - a fim de o identificarmos, avaliarmos, questionarmos e criticarmos em todos os seus contextos específicos". Nesse sentido, o modo como conceptualizamos a participação irá afetar significativamente o modo como refletimos sobre as expetativas criadas sobre os processos que a tornam possível. 
Este artigo começa o debate sobre o conceito de participação com a apresentação da teoria da metáfora conceptual (Lakoff \& Johnson, 2004), ou seja, pretende-se entender uma determinada ideia, neste caso a participação, através de outra, o talismã. A modelação metafórica como método de investigação baseia-se na ideia de que o conhecimento é estruturado através do estabelecimento de analogias entre áreas conceptuais (Pärn, 2017). Este texto propõe a metáfora do talismã como forma de entender a participação, enquanto elemento reconhecido, investido ritualisticamente de um poder benéfico e protetor. A participação, assim como os amuletos e talismãs, foi definida como (não) autêntica, atribuidora de poder simbólico, fantasmagórica, obscura, estética ou valiosa. Com base na literatura de áreas como os Estudos em Jornalismo, Estudos Culturais, Estudos em Educação e Ciências Políticas, este texto faz a ligação entre os debates em curso e propostas teóricas através da metáfora do talismã, com o objetivo de resgatar a participação ao reconhecê-la como força motriz, ao reconhecer o poder que ela representa, o seu papel protetor e a importância dos rituais que a moldam e a tornam autêntica. O objetivo deste artigo é reconhecer e valorizar a forma como as teorias que lidaram com a participação de forma consistente estão ligadas à metáfora do talismã e demonstrar a relevância e valor deste modo de pensar o processo participativo. Ao mesmo tempo, é importante considerar os limites da metáfora (que são simultaneamente um dos seus pontos fortes), uma vez que esta se baseia numa equação sempre imperfeita, o que necessariamente implica uma redução.

O conceito de talismã, com origem nas culturas grega e árabe, refere-se a um elemento mágico que acreditamos ter a capacidade de evitar o mal e atrair a boa sorte. Os amuletos e talismãs são símbolos, convertidos muitas vezes em objetos palpáveis. A credulidade humana permite que se lhe atribuam poderes e virtudes mágicas e extraordinárias (Hildburg, 1951; Lecouteux, 2014). O uso de talismãs recua à Antiguidade e a sua assimilação através de intercâmbios culturais moldou a sua criação. Possuir amuletos, com diferentes formas e de diferentes materiais, foi visto como uma prática fundamental para combater diferentes tipos de mal. Continuam a ser usados por pessoas com origens económicas e culturais diversas, embora tenham perdido alguma da sua aura enquanto prática sociocultural. Poderão, supostamente, ter um efeito curativo ou preventivo, mas o seu encanto tem estado também intimamente ligado ao aspeto decorativo. Por isso, para além de protegerem, os talismãs são símbolos de identificação ou ostentação e possuem valor estético (Martín Ansón, 2005).

A dualidade do talismã, enquanto símbolo com eventual poder e elemento decorativo indicador de estatuto social, é partilhada por várias conceptualizações relativas à natureza ambivalente e contraditória da participação. É possível que a metáfora do talismã ajude igualmente a perceber a relação entre a "simulação da participação simbólica" (Prado, 1986) e a sua "promessa de empoderamento" (Carpentier, 2016). Numa altura em que tantas plataformas de média e comunicação oferecem possibilidades interativas, devemos questionar-nos se a participação é um fetiche, desligado da realidade social, ou, antes, serve um propósito significativo, também como talismã. Simultaneamente, as decisões corporativas de convidar à participação do público podem ser consideradas 
preventivas, uma vez que seguem a tendência generalizada da lógica dos média digitais e convergentes, ou podem realmente atribuir estatuto ou valor aos contributos dos cidadãos. Do mesmo modo, o talismã requer um ritual específico para invocar o seu poder e garantir a sua autenticidade. De modo semelhante, o potencial democrático dos processos participativos é moldado pelas normas e agentes que gerem estas práticas.

\section{Abordagens À PARTicipaÇão}

Nas duas últimas décadas, e em especial nos últimos 10 anos, o interesse académico e industrial pela participação nos média e nos processos de comunicação tem produzido bastante material investigativo. Um número substancial abordou a participação nos e através dos média, se atendermos à útil diferenciação feita por Carpentier (2011a). Uma das razões para o sucesso deste tema tem que ver com as possibilidades interativas das novas tecnologias, dos média às plataformas. Além disso, a participação está intimamente ligada a outros conceitos relevantes, tais como a interação (Carpentier, 2011b), o envolvimento (Bergillos, 2017) ou capacitação (Barry \& Doherty, 2016).

Diversos fóruns de investigação, revistas e livros ilustram o interesse dos investigadores, um pouco por todo o mundo (Pasquali, Noguera Vivo \& Bourdaa, 2013). No âmbito da Cooperação Europeia em Ciência e Tecnologia (CECT), foi financiada uma ação subordinada ao tema "Transformar Públicos, Transformar Sociedades" (CECT, Ação ISogo6), tendo mobilizado um dos seus quatro grupos de trabalho para a "Interatividade e participação do público". Revistas académicas como Participations [volumes 9(2) e 10(1)], Communication Management Quarterly (volume 21), International Journal of Communication (volume 8), Communications (volume 3), International Journal on Média Management [volume 14(2)], Comunicazioni Sociali (volume 3), Interactions: Studies in Communication a Culture [volume 5(3)], Observatorio (OBS*) (volume 34) ou Media and Communication [volume $6(4)$ ], entre muitas outras, dedicaram números especiais a este objeto de estudo. Eventos académicos relevantes incluíram conversas entre estudiosos com diferentes formações teóricas. Por exemplo, o simpósio "Geração TransMédia", realizado em Praga, em 2012, foi um evento oportuno que serviu como ponto de encontro entre alguns dos académicos mais proeminentes nesta área. Os artigos publicados depois da conferência na Convergence [volume 19(3)] são referências-chave para qualquer investigador que esteja interessado nessas interpretações complexas e variadas acerca do significado de participação em ambiente média convergente e digital.

Ao longo de diversos debates discutiu-se o contexto no qual ocorre a participação e os desequilíbrios de poder que moldam as práticas participativas (Couldry \& Jenkins, 2014; Dahlgren, 2013; Jenkins \& Carpentier, 2013). Por um lado, os Estudos Culturais serviram como enquadramento para a análise da participação de públicos ativos. Por exemplo, os Estudos sobre Fãs, ou a pesquisa sobre comunidades de seguidores, debruçaram-se sobre as atividades de grupos que procuram uma relação mais próxima com os textos que consomem, assim como a sua crescente participação na construção da cultura. Os investigadores dos Estudos sobre Fãs realçam o facto de o público, organizado 
em comunidades, adotar uma perspetiva crítica em relação aos produtores. A cultura participativa é aqui definida como um contexto em constante mudança, no qual "em vez de se considerar que os mediadores e consumidores ocupam papéis separados, vemo-los como participantes que interagem entre si de acordo com um conjunto de regras que nenhum de nós entende inteiramente" (Jenkins, 2006, p. 3). A capacidade que os cidadãos têm hoje para produzir e editar mensagens, e para as distribuir gratuitamente através de diferentes média, é vista como a democratização da produção de conteúdo audiovisual. Contudo, Jenkins et al. clarificam que

não há uma única orientação ideológica (...) que detenha o monopólio das
virtudes de uma cultura mais participativa. (...) Assim como a cultura da
internet, a cultura participativa tem valências contraculturais e antiauto-
ritárias que refletem as suas raízes, mas também está cada vez mais in-
terligada com as formas comerciais e capitalistas da produção cultural e
tecnológica. (2016, p. 182)

Isto deve servir como um sinal de alerta sobre o facto de que não apenas os públicos e os fãs estão dispostos a aproveitar as oportunidades oferecidas pelas tecnologias digitais e média convergentes: a apropriação da cultura participativa pelas empresas (Deuze, 2008) veio complicar a situação.

Embora a cultura participativa não tenha surgido ligada a uma tecnologia específica, ou a um determinado momento histórico, tornou-se objeto de estudo nos anos 1980, quando autores como Fiske (1987) ou Jenkins (2006) analisavam, a partir de uma perspetiva culturalista, as colaborações e a produção coletiva de conhecimento de públicos ativos em relação aos textos veiculados pelos média. $O$ desenvolvimento dos computadores pessoais, a emergência da internet e o crescimento de tecnologias de banda larga foram algumas das tendências que aceleraram o interesse académico pela participação (Delwiche \& Jacobs Henderson, 2013) e ficaram associadas ao entusiasmo pela pesquisa sobre a comunicação interativa (Quiring \& Schweiger, 2008). Do ponto de vista da investigação em Comunicação e Média, a interatividade manteve certamente uma relação próxima com a participação, uma vez que ambos os termos foram amplamente discutidos enquanto possibilidades importantes criadas pelas tecnologias digitais. Andrejevic (2004), por exemplo, introduziu a ideia de interatividade participativa como promessa de convergência de novos média; como o acesso às ferramentas de produção e distribuição dos média, a fim de que os públicos possam ter um papel ativo durante a sua experiência.

À semelhança de vários conceitos-chave, a interatividade é (a par da participação) um termo complexo e usado de maneira inconsistente, sem ter uma definição clara e única, e com as diferentes áreas de pesquisa, da Sociologia, Psicologia à Informática, a tentarem fixá-la ou avaliá-la. No entanto, as definições são frequentemente imprecisas ou até mesmo contraditórias, já que abordam o conceito a partir de diferentes perspetivas, as quais incluem a interatividade enquanto processo de comunicação, como característica dos novos média ou como um elemento observado pelos utilizadores (Jensen, 2008; McMillan, 2006; Quiring \& Schweiger, 2008; Rafaeli, 1988). O aspeto mais importante 
da interatividade, no caso deste artigo, é o seu potencial para criar uma sensação de capacitação durante o processo comunicativo. Barry e Doherty (2017) defendem que a capacitação é uma forma dominante de interatividade e no discurso público existem referências constantes às suas eventuais ações, estratégias ou resultados, ainda que os exemplos específicos de interatividade usados dependam das tecnologias do seu tempo.

Ao mesmo tempo, a participação é considerada uma expressão da ação política, ou envolvimento político. Neste sentido, está sempre enquadrada, até certo ponto, com as lutas que envolvem a identificação dos desequilíbrios de poder (Carpentier, 2011a; Delwiche, 2013). Como refere Carpentier (2011b), a teoria política apela à diferenciação entre o que é a participação e outros termos que não poderão ser-lhe equiparados, mesmo que relacionados, como o acesso ou a interatividade. Vendo por essa perspetiva, a participação ainda funciona numa relação com diferentes conceitos, mas as suas características definidoras tornam-se em processos de tomada de decisões e desequilíbrios de poder que os influenciam. Carpentier (2014, p. 1002) define participação "como uma situação na qual os atores envolvidos em processos de tomada de decisões (formais ou informais) se posicionam entre eles através de relações de poder que são (em certa medida) igualitárias". Existem formas maximalistas e minimalistas de participação, dependendo de quem mantém ou partilha o poder sobre os processos participativos e os seus resultados. De um ponto de vista analítico, esta distinção é muito útil. Carpentier (2016), baseando-se nessa noção, desenvolveu aquele que deverá ser o modelo analítico mais variado de interpretação dos processos de média participativos. Seria importante notar, contudo, que o facto de as formas maximalistas de participação oferecerem uma distribuição de poder mais equilibrada, pelos agentes responsáveis pelas tomadas de decisão, não significa que esses mesmos processos sejam sempre os desejados. De modo semelhante, o envolvimento em práticas participativas minimalistas que criam a ilusão de empoderamento não significa que estamos perante um processo democrático. Nesse sentido, e mais do que nunca, é necessário defender o conceito de participação.

Durante uma conversa inspiradora entre os dois representantes das abordagens ao conceito de participação na investigação em Comunicação e Média, Jenkins e Carpentier (2013) sugerem a desconstrução de teorias tradicionais, com o objetivo de podermos avançar para um modelo de análise integrado e complementar, que ofereça uma linguagem variada que nos permita comunicar a complexidade do conceito. Uma das conclusões do trabalho destes autores aponta ao reconhecimento de que uma participação total ou uma cultura participativa ideal são objetivos utópicos e, consequentemente, não alcançáveis, mas que, ainda assim, podem servir como pontos de referência para uma avaliação crítica das práticas participativas. Baseada nessa ideia, a natureza fantástica ou quimérica da participação surge como primeira justificação para analisarmos a participação como um talismã.

\section{A FANTASIA PARTICIPATIVA}

À semelhança do que sucede com os talismãs, existe, teoricamente, uma tensão entre o princípio abstrato da participação e o seu caráter real. Se os talismãs estão, 
geralmente, ligados a circunstâncias místicas, a participação foi interpretada como um mito desconfortável (Domingo, 2008), como obscura (Quandt, 2018) ou um fetiche democrático (Carpentier, 2011a). Daí que seja colocado geralmente na esfera do imaginário ou do infundado.

O conceito Lacaniano de fantasia foi introduzido nos debates teóricos acerca da participação por Carpentier (2014), o qual evita uma interpretação exclusivamente negativa do termo. Segundo García-Catalán (2012), Lacan propõe conceitos obscuros que acabam por gerar luz. Carpentier (2014) recorre a Lacan para definir fantasia como algo com capacidades protetoras e geradoras. Embora se apresente como força motriz ligada ao desejo, encerra em si também o "paradoxo de simultaneamente desejar o objeto e recear a impossibilidade de satisfazer tal desejo" (p. 1003). Relativamente à participação, ele associa o conceito de fantasia à sua própria teoria de formas maximalistas de participação e ao conceito de Pateman (1970) de participação por inteiro; o objetivo de alcançar relações de poder equilibradas entre todos os atores, de todos os níveis sociais:

este ponto de chegada é inalcançável e utópico - fantasmagórico - mas serve, sem sombra de dúvida, como força motriz para as tentativas de "aprofundar a revolução democrática" (Mouffle, 1988, p. 42), para uma "democratização da democracia" (Giddens, 1994, p. 113) ou para uma "cultura mais participativa". (Carpentier, 2014, p. 1004)

Contudo, Carpentier (2014) observa que a fantasia participativa interage com outras fantasias (a da universalidade e homogeneidade, a da liderança e a da liberdade e ação) o que - a vários níveis - cria obstáculos, limites estruturais e dependências entre práticas e fantasia participativas.

No que diz respeito à estrutura conceptual da participação como um talismã, a fantasia participativa demonstra pertencer a um enquadramento abstrato, à semelhança de tensões com outras fantasias que prejudicam ou protegem o seu potencial. De acordo com a interpretação Lacaniana de fantasia, conseguimos percebê-la melhor como forma de capacitação. Participamos e estamos envolvidos no enquadramento do nosso fantasma. Como realça Carpentier (2014, p. 1013), "o foco na participação como uma fantasia também nos permite mostrar a complexidade das práticas participativas e os seus impulsos, profundamente arreigados, que, por vezes, funcionam a seu favor e, outras vezes, contra".

\section{A AUTENTICIDADE DA PARTICIPAÇÃo}

Definir participação significa, geralmente, diferenciá-la daquilo que não é. Tal facto tem sido particularmente importante nestes últimos anos, em que a participação se tornou tão presente em várias áreas do saber. No campo da Comunicação, alguns autores voltaram-se para conceitos intimamente ligados ao sistema conceptual do talismã para tentar estabelecer qual o tipo de participação mais significativo: 
as tentativas de contrariar este apagamento (do significado) da participação basearam-se na criação de sistemas de significado dicotómicos. Nestas dicotomias, formas específicas de participação são descritas como "reais" e "autênticas", enquanto outras são descritas como "falsas" e "pseudo". (Carpentier, 2007, p. 87)

Por exemplo, Prado (1986) aponta a natureza simbólica da participação em casos nos quais ferramentas ou enquadramentos que realcem a voz dos agentes sociais e minorias não são providenciados. No campo da comunicação para o desenvolvimento e comunicação participativa, Servaes (1999, p. 187) sublinha que "as visões utópicas da comunicação de desenvolvimento foram chamadas de participação 'genuína' e 'autêntica', quando comparadas com a participação manipuladora e pseudo-participação”. Esta ilusão que simula processos de participação e intimidade com os públicos foi identificada pela investigação em Comunicação e Média (McQuail, 2005, p. 444), mas havia sido anteriormente definida pelas Ciências Políticas, como relembra Carpentier (2007):

no campo da dita participação política, por exemplo, Verba (1961, pp. 220-

221) aponta para a existência de uma "pseudo-participação", na qual a aten-

ção não está focada na criação de uma situação onde a participação seja

possível, mas do sentimento de que é possível. (Carpentier, 2007, p. 87)

Os processos (pseudo) participativos e práticas de envolvimento estão muito presentes nos média, embora cada vez mais interligados com os interesses promocionais das empresas e das intenções dos públicos envolvidos (Jenkins et al., 2016). No primeiro caso, é possível que as empresas se aproveitem da energia, tempo, esforço e criatividade dos públicos e utilizadores, cuja atividade e dedicação enriquecem a produção cultural contemporânea e a comunicação política. No segundo caso, é possível que a participação se torne uma demonstração de compromisso afetivo com ideias, valores e argumentos. Num momento em que as redes sociais e a cultura popular são cruciais para a comunicação política (Jenkins, Shresthova, Gamber-Thomson \& Zimmerman, 2016), a exploração dos convites que enquadram a participação em diferentes contextos poderá oferecer-nos um entendimento variado dos acordos, tensões ou "contratos de autenticidade" (Enli, 2015) que estes processos facilitam. No entanto, segundo McQuail (2005, p. 444), "na prática é difícil distinguir, de uma forma empírica, a ligação 'real' da ligação 'artificial'". Mas ainda podemos ver estas iniciativas como estratégias para a construção de autenticidade mediada ou um apelo à participação (Klein Shagrir, 2018). Segundo Enli (2015), a autenticidade mediada beneficia das práticas participativas, uma vez que, geralmente, estas servem como catalisadores da espontaneidade, imediatismo, normalidade ou ambivalência nos média.

\section{O RITUAL DA PARTICIPAÇÃo}

A autenticidade da participação, ou a perceção de participação autêntica, advém geralmente do ritual que a torna possível. Não se trata da participação em si, antes do 
processo ou evento que ocorre, o conhecimento (mágico) exigido para que tal aconteça, incluindo as condições necessárias para ativar o seu poder. As práticas participativas são complexas, únicas e, por vezes, contraditórias; baseiam-se em processos moldados pela interação entre agentes cuja relação de poder é (des)igual. De um ponto de vista cultural, James Carey (1989), que é uma referência nesta área, apresentou a comunicação como um ritual, um processo simbólico que (re)produz e transforma a realidade. O modelo de ritual de Carey (1990) está intimamente ligado a termos como associação, partilha e participação. De uma forma similar, para que os talismãs sejam considerados autênticos é importante que estejam garantidas certas condições durante a sua preparação e implementação, tais como o momento em que deverão ser aplicados, a pessoa que produz os objetos ou oficia o ritual. Helck (1984, citado em Velázquez Brieva, 2004, p. 34) explica que os rituais esotéricos começaram por ser realizados por xamãs ou padres que conheciam as práticas e possuíam qualidades especiais para invocar poderes e virtudes. Posteriormente, através da escrita e aprendizagem, este exercício estendeu-se a outros grupos sociais, que tinham acesso às ferramentas e conhecimentos necessários para produzir amuletos. Existe um certo paralelismo entre a história dos rituais talismânicos e as "ondas de democratização dos média" (Carpentier, Dahlgren \& Pasquali, 2013) que permitiram um acesso mais fácil às ferramentas participativas, antes limitadas a especialistas ou elites. Curiosamente, ao sublinharem o eventual perigo de incluir a retórica participativa na análise do papel do jornalismo em democracia, Peters e Witschge (2015) usam repetidamente o verbo invocar para avisar contra o discurso celebratório da democratização dos média através da participação. Além disso, Carpentier (2014) avisa que há uma fantasia desaparecida em torno do profissional dos média que leva a uma fantasia democrática-populista que desemboca na ideia de que os profissionais de média são desnecessários. Em suma, parece que há a necessidade de identificar quem participa, a relação entre pessoas comuns e especialistas que dirigem o processo e a importância de contextualizar a participação enquanto ritual.

Um segundo elemento que serve para fundamentar a ideia do ritual é o facto de os média nos convidarem a participar. Este é um aspeto essencial do modelo de ritual de Carey, mas já outros autores de abordagens socioculturais haviam sublinhado a natureza convidativa da participação (Gulbrandsen \& Just, 2011; Johnson, 2007). Hille e Bakker (2013, p. 4) chamam a atenção para o facto de "o público precisar de ser estimulado e convidado pelos média antes de oferecer o seu contributo (relevante). Isto sugere que a participação não é o resultado da oferta de oportunidades, mas está também dependente da 'participação' ativa do próprio meio". Johnson (2007, p. 78) afirma que "a utilização de múltiplas plataformas permite que o público entre em novos espaços culturais, mas o significado desse convite permanece ambíguo, sendo que, ao mesmo tempo, atribui poder e explora o público". Gaventa (2007) estabelece três categorias espaciais relativas à participação; sendo uma delas os "espaços de convite". Ao contrário dos espaços fechados ou criados, estes espaços são aqueles nos quais há um convite explícito para que diferentes agentes tomem decisões. Relativamente à televisão, Ross (2008) categoriza três tipos de convite: aberto, orgânico e obscuro. Gulbrandsen e Just salientam que 
a relação entre convite e participação passa a ser o principal receio, uma vez que ficou claro que o modo como os utilizadores são convidados a participar pode condicionar a sua participação - não no sentido de determinar a participação, mas criando a estrutura ou caminho que poderemos seguir ou contrariar (Just, 2008). Ao mesmo tempo, contudo, qualquer convite específico está condicionado pela já existente participação - qualquer convite é também uma resposta. (2011, p. 1104)

De uma outra perspetiva, Carpentier (2011b) defende a natureza convidativa da participação, mas afasta-se do convite hierárquico onde apenas alguns têm controlo sobre o processo. Vira-se para o conceito de mudança social por convite que reconhece a ação do participante e o seu direito de não participar:

concordo com Foss e Griffin (1995, p. 3), que contrapõem convite a persuasão (sendo esta última alimentada pelo "desejo de controlo e domínio") e com Greiner e Singhal (2009, p. 34), que desenvolveram o conceito de mudança social por convite, o qual "procura substituir intervenções que comunicam através de apelos à imaginação e esforços inspiracionais". Este tipo de reflexões permite que a participação surja por convite, o que implica que a sua aplicação seja definida como contraditória à sua lógica e que o direito a não participar seja respeitado. (Carpentier, 2011, p. 22)

Na sua conversa sobre participação e política, Allen et al. (2014) acrescentam mais um pormenor às ideias apontadas. O convite é parte integrante do processo participativo, mas, por vezes, é a sua ausência que promove o ativismo. Por essa razão, dizemos que a participação advém do envolvimento individual que alimenta o ativismo. Nesse sentido, Dahlgren (2013, p. 20) acrescenta que "o envolvimento subjetivo que lhe é subjacente e a participação de que daí resulta pode ter diversos graus de intensidade afetiva (...). As circunstâncias políticas irão também moldar a natureza emocional da participação de indivíduos e grupos". Assim sendo, o convite não terá necessariamente de vir de um agente poderoso que torne a participação possível, mas antes do próprio processo participativo (talismã), que convide à ação e crie um sentimento de empoderamento.

\section{O VALOR ESTÉTICO DA PARTICIPAÇÃo}

Um último aspeto que suporta a ideia de participação enquanto talismã é o seu valor estético. Alguns autores observaram que em alguns contextos de comunicação a participação é sobretudo importante devido ao que representa, mais do que propriamente pelos resultados do seu processo. A apropriação, por parte das empresas, da participação e cultura participativa (Deuze, 2008) tende a significar que as possibilidades de interatividade e colaboração não são, em muitos casos, mais do que uma demonstração. Por exemplo, na área do jornalismo,

à medida que cada vez mais meios de informação foram criando secções de comentários e formatos participativos, tornou-se moda faze-lo, e muitos 
faziam-no porque toda a gente o fazia. Este efeito dominó tornou-se bastante evidente; não ser deixado para trás e parecer "moderno" eram as principais motivações. (Quandt, 2018, p. 38)

Grande parte desta empolgação à volta da participação está muito relacionada com as possibilidades criadas pelas novas tecnologias e plataformas. Mosco (2017) volta-se para o conceito de totem, um sinónimo de talismã, para explicar como estas ferramentas e sistemas têm diferentes significados:

os futuros sistemas de internet, principalmente a "internet das coisas", são mais do que meros instrumentos para atingir objetivos económicos ou políticos. São também objetos culturais com diversos significados. À semeIhança dos totens tribais, possuem qualidades mágicas que personificam o sublime. (...) Dão reconhecidamente pequenos passos para fundamentar estas crenças míticas, mas também participam num complexo tecnológico que contém um poder político, económico e cultural significativo. (Mosco, 2017, p. 100)

A participação, enquanto talismã, funciona como símbolo de poder e garante de estatuto. No entanto, existe uma grande diferença: hoje em dia, as pedras preciosas e os talismãs são produzidos aos milhões. Os seus poderes mágicos foram relegados para um papel secundário, pelo que funcionam principalmente como facilitadores de reconhecimento social ou mera decoração. Do mesmo modo, a participação nos meios de comunicação foi implementada, maioritariamente, como forma cosmética de integração dos públicos, mas necessita ainda de resgatar os valores democráticos, pluralistas e culturais que representa.

\section{Conclusão}

Recentemente, Quandt (2018, p. 45) defendeu o "desenvolvimento de teorias integradoras sobre as condições da participação que não sejam impulsionadas nem por pensamentos mágicos, nem por pensamentos trágicos". Com base em abordagens culturais e políticas, Jenkins e Carpentier (2013) consideraram que a reconstrução teórica e o entendimento partilhado dos conceitos principais definem as práticas participativas. Todos eles defendem que investigações futuras acerca da participação deverão ter em consideração as complexidades e ambivalências deste objeto de pesquisa.

Inspirado por Lakoff e Johnson (1980), este artigo apresentou a metáfora da participação como talismã, como forma de percebê-la enquanto - pelo menos em parte - elemento simbólico à volta do qual um ritual é realizado para imbui-lo de poder. Anteriores conceptualizações e categorizações haviam já apresentado aspetos relacionados com esta metáfora: a participação articula-se com o poder, invoca valores democráticos, é autêntica ou um fetiche, é simbólica ou um mito, requer um certo ritual que capacita e promove o envolvimento emocional, ... Este texto tentou organizar, de forma coerente, 
quatro aspetos da mencionada metáfora: a fantasia participativa, a autenticidade da participação, o seu ritual e o seu valor estético.

A participação é relevante. E o modo como a pensamos, metaforicamente falando, também é relevante. Ao abrigo da investigação em Comunicação e Média, a participação enquanto talismã convida-nos a aceitar a ambivalência do conceito e a tentar incluir os contributos dos diversos campos. Esperamos que este texto também sirva como guia para futuras conceptualizações da metáfora. Se as ações e práticas participativas continuarem a ser-lhe associadas, talvez possam reforçar o seu poder. A interpretação da participação como uma fantasia traz para a discussão uma série de questões, não só relacionadas com a sua autenticidade ou os rituais envolvidos na sua criação, mas também a sua eventual utilização em diferentes contextos, o sentimento de envolvimento e capacitação gerados neste quadro. Se entendermos a participação como um talismã, podemos protegê-la, resgatá-la, ao reforçarmos a crença no seu potencial. Ao recuperarmos a fé no seu poder, iremos ficar mais bem preparados para a democracia emocional e sentimental (Arias Maldonado, 2016; Wahl-Jorgensen, 2018) em que vivemos hoje.

Tradução: Helena Antunes

\section{REFERÊNCIAS}

Allen, D., Bailey, M., Carpentier, N., Fenton, N., Jenkins, H., Lothian, A., Qiu, J. L., Schäfer, M. T. \& Srinivasan, R. (2014). Participations: dialogues on the participatory promise of contemporary culture and politics. Part 3: Politics. International Journal of Communication, 8, 1129-1151.

Andrejevic, M. (2004). Reality TV: the work of being watched. Lanham: Rowman and Littlefield.

Arias Maldonado, M. (2016). La democracia sentimental. Política y emociones en el siglo XXI. Madrid: Página Indómita.

Barry, M. \& Doherty, G. (2017). What we talk about when we talk about interactivity: empowerment in public discourse. New Media Q Society, 19(7), 1052-1071. https://doi.org/10.1177/1461444815625944

Bergillos, I. (2017). Two sides of the same coin? A reflection on the relation between engagement and participation in media. Comunicación y Hombre, 14, 119-134.

Carey, J. W. (1989). Communication as culture. Winchester, MA: Unwin Hyman.

Carey, J. W. (1990). Technology as a totem for culture: and a defense of the oral tradition. American Journalism, $7(4), 242-251$.

Carpentier, N. (2007). Participation and media. In B. Cammaerts \& N. Carpentier (Eds.), Reclaiming the media: communication rights and democratic media roles (pp. 57-78). Bristol: Intellect.

Carpentier, N. (2011a). Media and participation. Bristol \& Chicago: Intellect.

Carpentier, N. (2011b). The concept of participation - if they have access and interact, do they really participate? Communication Management Quarterly, 21, 13-36. 
Carpentier, N. (2014). "Fuck the clowns from Grease!!" Fantasies of participation and agency in the YouTube comments on a Cypriot Problem documentary. Information, Communication Q Society, 17(8), 1001-1016. https://doi.org/10.1080/1369118X.2013.875582

Carpentier, N. (2016). Beyond the ladder of participation: an analytical toolkit for the critical analysis of participatory media processes. Javnost - The Public, 23(1), 70-88. https://doi.org/10.1080/13183222.2016 .1149760

Carpentier, N., Dahlgren, P. \& Pasquali, F. (2013). Waves of media democratization: a brief history of contemporary participatory practices in the media sphere. Convergence: The International Journal of Research into New Media Technologies, 19(3), 287-294.

Couldry, N. \& Jenkins, H. (2014). Participations: dialogues on the participatory promise of contemporary culture and politics. International Journal of Communication, 8, 1107-1112.

Dahlgren, P. (2013). The political web. Media, participation and alternative democracy. Londres: Palgrave Macmillan.

Delwiche, A. (2013). The new left and the computer underground. Recovering political antecedents of participatory culture. In A. Delwiche \& J. Jacobs Henderson (Ed.), The participatory cultures handbook (pp. 10-21). Nova lorque: Routledge.

Delwiche, A. \& Jacobs Henderson, J. (2013). The participatory cultures handbook. Nova lorque: Routledge.

Deuze, M. (2008). Corporate appropriation of participatory culture. In N. Carpentier \& S. Livingstone (Eds.), Participation and media production: critical reflections on content creation (pp. 27-40). Newcastle upon Tyne: Cambridge Scholars Publishers.

Domingo, D. (2008). Interactivity in the daily routines of online newsrooms: dealing with an uncomfortable myth. Journal of Computer-Mediated Communication, 13, 680-704. https://doi. org/10.1111/j.1083-6101.2008.00415.x

Enli, G. (2015). Mediated authenticity: how the media constructs reality. Nova lorque e Londres: Peter Lang.

Fiske, J. (1987). Television culture: popular pleasures and politics. Londres: Routledge.

Foss, S. \& Griffin, C. (1995). Beyond persuasion: a proposal for an invitational rhetoric. Communication Monographs, 62(1), 2-18. https://doi.org/10.1080/03637759509376345

Garcia-Catalán, S. (2012). Hipertexto y modelización cinematográfica en la divulgación neurocientífica audiovisual. A propósito de 'Redes' de Eduard Punset. Tese de doutoramento, Universidade Jaume I, Castellón, Espanha.

Gaventa, J. (2007). Finding the spaces for change: a power analysis. IDS Bulletin, 37, 23-33. https://doi. org/10.1111/j.1759-5436.2006.tboo320.x

Greiner, K. \& Singhal, A. (2009). Communication and invitational social change. Journal of Development Communication, 20(2), 31-44.

Gulbrandsen, I. T. \& Just, S. N. (2011). The collaborative paradigm: towards an invitational and participatory concept of online communication. Media, Culture Q Society, 33(7), 1095-1108. https://doi. org/10.1177/0163443711416066

Hildburgh, W. L. (1951). Psychology underlying the employment of amulets in Europe. Folklore, 62 (1), $231-251$. https://doi.org/10.1080/0015587X.1951.9718026 
Hille, S. \& Bakker, P. (2013). I like news. Searching for the Holy Grail of social media: The use of Facebook by Dutch news media and their audiences. European Journal of Communication, 28(6), 663-680.

Jenkins, H. (2006). Convergence culture: where old and new media collide. Nova lorque: New York University Press.

Jenkins, H. \& Carpentier, N. (2013). Theorizing participatory intensities: a conversation about participation and politics. Convergence: The International Journal of Research into New Media Technologies, 19(3), $265-286$.

Jenkins, H., Ito, M. \& boyd, d. (2016). Participatory culture in a networked era. Cambridge: Polity Press.

Jenkins, H. Shresthova, S. Gamber-Thomson, L. \& Zimmerman, A. (2016). By any media necessary: the new youth activism. Nova lorque: New York University Press.

Jensen, J. F. (2008). The concept of interactivity - revisited: four new typologies for a new media landscape. In J. Masthoff, S. Panabaker, M. Sullivan \& A. Lugmayr (Eds.), Atas da $1^{a}$ Conferência Internacional "Designing Interactive User Experiences for TV and Video" (pp. 129-132). Mountain View: Association for Computing Machinery.

Johnson, D. (2007). Inviting audiences in. New Review of Film and Television Studies, 5(1), 61-80.

Klein Shagrir, O. (2018). Para-interactivity and the appeal of television in the digital age. Londres: Lexington Books.

Lakoff, G. \& Johnson, M. (1980). Metaphors we live by. Chicago e Londres: University of Chicago Press.

Lecouteux, C. (2014). The high magic of talismans and amulets. Vermont: Inner Traditions.

Martín Ansón, M. L. (2005). Amuletos-talismanes para caballos, en forma de creciente, en la España medieval. Archivo Español de Arte, 309, 5-21.

McMillan, S. J. (2006). Exploring models of interactivity from multiple research traditions: users, documents and systems. In L. Lievrouw \& S. Livingstone (Eds.), The handbook of new media (pp. 206-229). Londres: Sage.

McQuail, D. (2005). McQuail's mass communication theory. Londres: Sage.

Mosco, V. (2017). Becoming digital. Toward a post-internet society. Bingley: Emerald Publishing.

Pärn, K. (2017). Metaphorical modelling as research method in semiotics. Punctum, 3(2), 33-60. https://doi. org/10.18680/hss.2018.0003

Pasquali, F., Noguera Vivo, J. M. \& Bourdaa, M. (2013). Emerging topics in the research on digital audiences and participation. An agenda for increasing research efforts. Comunicazioni Sociali, 3, 329-336.

Pateman, C. (1970). Participation and democratic theory. Cambridge: Cambridge University Press.

Peters, C. \& Witschge, T. (2015). From grand narratives of democracy to small expectations of participation. Journalism Practice, 9(1), 19-34. https://doi.org/10.1080/17512786.2014.928455

Prado, E. (1986). Garantizar la participación y el pluralismo. In E. Bustamante \& J. Villafañe (Eds.), La televisión en España mañana. Modelos televisivos y opciones ideológicas (pp. 179-185). Madrid: Siglo XXI.

Quiring, O. \& Schweiger, W. (2008). Interactivity: a review of the concept and a framework for analysis. Communications, 33, 147-167. https://doi.org/10.1515/COMMUN.2008.009 
Quandt, T. (2018). Dark participation. Media and Communication, 6(4), 36-48. https://doi.org/10.17645/mac. v6i4.1519

Rafaeli, S. (1988). Interactivity. From new media to communication. In R. P. Hawkins, J. M. Wiemann \& S. Pingree (Eds.), Advancing Communication Science: merging mass and interpersonal processes (pp. 110-134). Newbury Park: Sage.

Reifová, I. \& Svelch, J. (2013). Shrinking the grand narratives in theorizing participation and new media. Convergence: The International Journal of Research into New Media Technologies, 19(3), 261-264.

Ross, S. M. (2008). Beyond the box: television and the internet. Victoria: Blackwell.

Servaes, J. (1999). Communication for development. One world, multiple cultures. Cresskill: Hampton Press.

Velázquez Brieva, F. (2004). Análisis tipológico y contextual de los amuletos fenicio-púnicos en el mediterráneo centro-occidental. Tese de doutoramento, Universidade Autónoma de Madrid, Madrid, Espanha.

Wahl-Jorgensen, K. (2018). Emotions, media and politics. Cambridge: Polity Press.

\section{NotA BIOGRÁFICA}

Ignacio Bergillos é Professor no Centro de Ensino Superior Alberta Giménez, na Universidade Pontifícia Comillas, em Maiorca, Espanha, onde desempenha as funções de Diretor do Departamento de Ciências da Comunicação. Doutorado em Comunicação Audiovisual e Publicidade pela Universidade Autónoma de Barcelona, desenvolve investigação sobre meios tecnológicos e inovação, mudanças nas indústrias mediáticas e a relação entre as audiências e os profissionais no contexto de uma cultura participativa.

ORCID: https://orcid.org/0000-0002-9333-8056

Email: ibergillos@cesag.org

Morada: Departamento de Ciências da Comunincação, CESAG - Universidade Pontificia Comillas, Costa de Saragossa, 16, 07013, Palma de Maiorca, Ilhas Baleares, Espanha

* Submetido: 19/02/2019

*Aceite: 11/05/2019 